\title{
Finger blood flow in patients with low tension glaucoma and primary open-angle glaucoma
}

\author{
T Usui, K Iwata
}

\begin{abstract}
Finger blood flow was studied by means of laser Doppler flowmetry in 12 patients with low tension glaucoma (LTG), 12 patients with primary open-angle glaucoma (POAG) and 12 normal subjects. Baseline flow, flow after immersion of the hand in warm water $\left(+40^{\circ} \mathrm{C}\right)$, and flow after exposure of the hand in cold water $\left(+4^{\circ} \mathrm{C}\right)$ were measured. Statistically significant differences were not found in each flow between the three groups of the patients $(p>0.05)$. Vasospastic response to warm and cold water was observed in $25 \%$ of LTG patients, $17 \%$ of POAG patients, and $25 \%$ of normal subjects. There was no significant difference between LTG, POAG, and normal subjects in finger blood flow.
\end{abstract}

The pathogenesis of optic nerve damage in low tension glaucoma (LTG) and in primary open angle glaucoma (POAG) is still unknown. Recently ${ }^{1-4}$ some investigators reported a relationship between LTG and vasospasm. Drance et $a l^{5}$ measured blood flow in the finger in LTG patients with/without migraine and normal subjects with/without migraine. They noted that the mean baseline flow and mean flow after exposure to cold water $\left(+4^{\circ} \mathrm{C}\right)$ were lower in patients with LTG, and suggested that vasospastic events might play a role in the damage of the optic nerve head in LTG patients. Corbett et $a l^{1}$ and Phelps and Corbett ${ }^{2}$ reported that migraine was frequent in LTG patients; however, our study on the prevalence of migraine in LTG and $P O A G^{6}$ revealed no significant relationship between migraine and LTG or POAG. Therefore we attempted to investigate further the relation between vasospasm and LTG or POAG, measuring finger blood flow and its response to warmth and cold.

Department of Ophthalmology, Niigata University School of Medicine, Niigata, Japan T Usui

K Iwata

Correspondence to: Dr Tomoaki Usui, Department of Ophthalmology, Niigata University School of Medicine, 1 Asahimachi, Niigata 951, Japan.

Accepted for publication 17 May 1991

\section{Patients and methods}

The patients with LTG had typical glaucomatous optic disc cupping and visual field defects in at least one eye, and intraocular pressure (IOP) without therapy remained lower than $21 \mathrm{~mm} \mathrm{Hg}$ on repeated measurements; they had no history of retrobulbar neuritis, anterior ischaemic optic neuropathy, or intracranial lesion. The patients with POAG had typical glaucomatous optic disc cupping and visual field defects, and pretreatment IOP of $21 \mathrm{~mm} \mathrm{Hg}$ or more. Tested normal subjects had no history of vasospastic diseases, such as migraine or Raynaud's disease, and no abnormal ocular findings except refractive error in both eyes. Informed consent was obtained from each subject after explanation of the purpose of the study.

All subjects were seated and adapted themselves in a quiet air-conditioned room. The tests lasted about 10 minutes during which the subjects were not allowed to talk or move.

The laser Doppler flowmeter used in this study, ALF21 (Advance Co, Japan) had a low power $(2 \mathrm{~mW})$ semiconductor laser source, producing light at $780 \mathrm{~nm}$ wavelength. The volume sampled by the probe was about $1 \mathrm{~mm}^{3}$. The laser light was delivered to the skin via a flexible optical fibre. The back scattered light consisted of Doppler-shifted light reflected from moving red blood cells and unshifted light reflected from stationary tissue. The back scattered light, both Doppler-shifted and unshifted, was led by another optical fibre from the tissue surface to a photodetector. The signal was processed and amplified to reach a high signal-to-noise ratio, analysed, and was displayed in real time. Values of tissue blood flow were expressed in $\mathrm{ml}$ blood/ minute/ $100 \mathrm{~g}$ tissue. The output signal from the flowmeter was recorded on paper with penrecorder (U-228, Advance Co, Japan).

After the probe of the laser Doppler flowmeter was attached to the skin of the middle finger in the subject's right hand by double adhesive tape, the hand was covered with a thin $(0.04 \mathrm{~mm})$ glove made of polyethylene. A baseline flow was decided when a steady baseline reading was achieved. The right hand was then immersed in warm water $\left(+40^{\circ} \mathrm{C}\right)$ for 2 minutes, and the flow was monitored until a maximum flow was reached after immersion in warm water. The right hand was then placed in ice cold water $\left(+4^{\circ} \mathrm{C}\right)$ for 10 seconds, and the flow was monitored for the next several minutes. After immersion in the water the hand was wiped mildly over the glove in order to avoid the influence of heat of evaporation. Blood pressure was also recorded during the test. Student's $t$ test was used for the statistical analysis, and the statistically significant level was taken as $\mathrm{p}<0.05$.

\section{Results}

This study was completed by a total of 36 subjects, including 12 patients with LTG, 12 


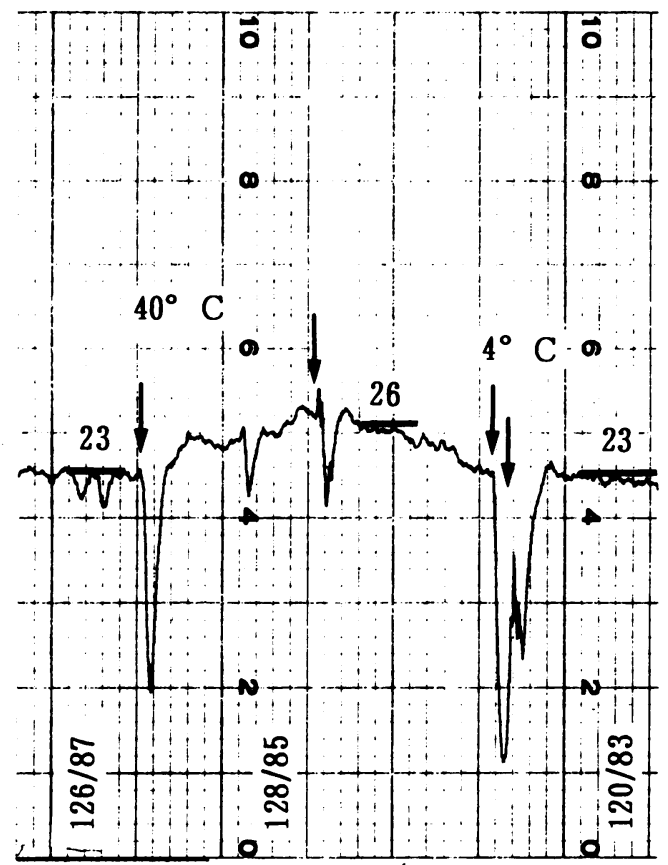

Figure 1 Tracing of finger blood flow in a POAG patient. Normal response to warm and cold water was noted. Values of blood pressure were expressed as $\mathrm{mm} \mathrm{Hg}$.

patients with POAG, and 12 normal subjects. The mean age was $47 \cdot 7$ years (SD 8.6) (range 32 61 years) in LTG, 51.7 years (SD 11.5) (range 36-68 years) in POAG, and $44 \cdot 0$ (SD 11.6) years (range 31-63 years) in normal subjects. The mean age of each of the three groups showed statistically no significant difference $(p>0.05)$. The mean untreated IOP was $14.6 \mathrm{~mm} \mathrm{Hg}$ (SD 2.9 ) in LTG, $27.9 \mathrm{~mm} \mathrm{Hg}$ (SD 4.8) in POAG, and $15.2 \mathrm{~mm} \mathrm{Hg}$ (SD 3.2) in normal subjects.

The patients in Figs 1 and 2 showed normal

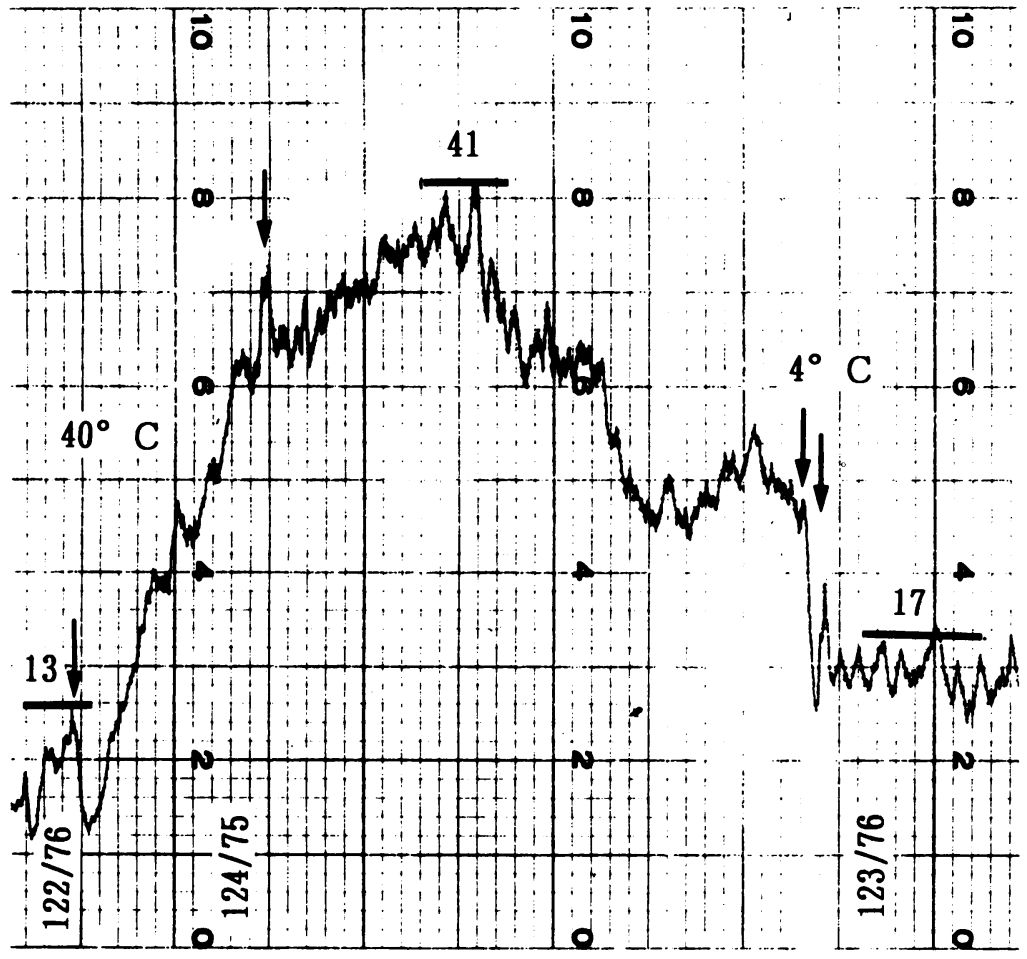

Figure 3 Tracing of finger blood flow in a normal subject. Vasospastic response was demonstrated. The flow had marked response to warm and cold water, but without recovery to baseline flow. Values of blood pressure were expressed as $\mathrm{mm} \mathrm{Hg}$.

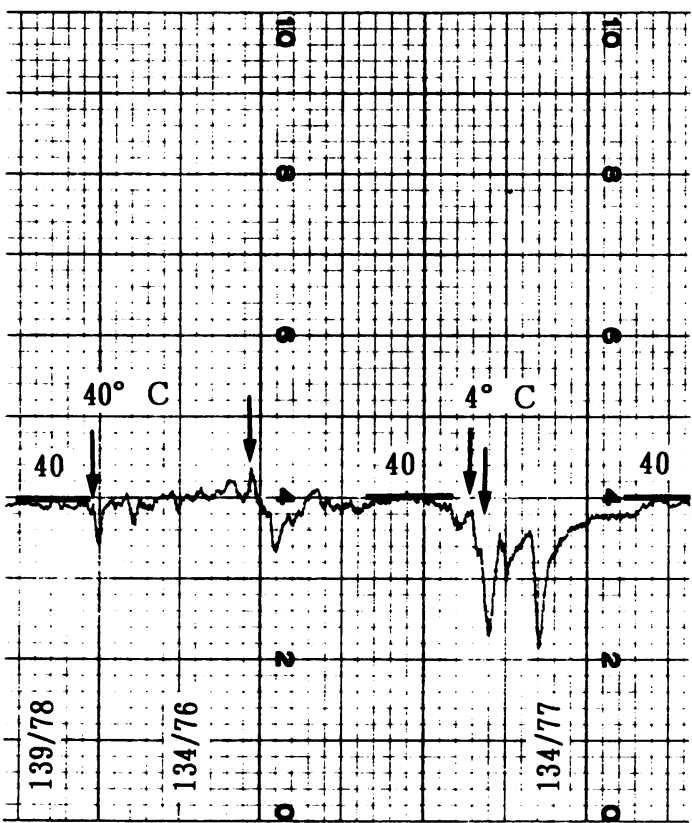

Figure 2 Tracing of finger blood flow in a LTG patient. Normal response to warm and cold water was noted. Values of blood pressure were expressed as $\mathrm{mm} \mathrm{Hg}$.

response to warm and cold water. They showed little increase in flow after exposure to the warm water and a decrease in flow during and after a short exposure to cold water, but the flow quickly returned to baseline. Figs 3 and 4 gave the vasospastic response according to Drance et al. ${ }^{5}$ The patients had marked response to warm and cold water, but without recovery to baseline flow. Three of 12 LTG patients, two of 12 POAG patients, and three of 12 normal subjects showed this response.

Finger blood flows in LTG, POAG, and normal subjects are summarised in Table 1. Baseline flow, flow after heat, and flow after cold in LTG patients were somewhat lower than those in POAG patients or normal subjects. However, no statistically significant difference was found in the three groups $(p>0.05)$. Furthermore, we calculated flow after heat/baseline flow, flow after cold/baseline flow, and flow after heat/flow after cold. Again there was no statistically significant difference in the three groups $(p>0.05)$.

\section{Discussion}

Laser Doppler flowmetry (LDF) is a clinically useful method of measuring local blood flow non-invasively and continuously. ${ }^{7-12}$ Usually LDF is applied to studies of skin blood flow, because it gives a continuous signal and is applicable to any region, and the measuring depth is limited to cutaneous tissue. ${ }^{1314}$

Blood flow through cutaneous arteriovenous anastomoses is controlled by specific thermoregulatory reflexes, whereas capillary blood flow is the target of local temperature effects. ${ }^{15} 16$

Drance et al, ${ }^{5}$ applying LDF, reported that the mean baseline flow and mean flow after exposure to cold water were lower in LTG patients. However, in our series a statistical significant difference was not found $(p>0.05)$. They found that $65 \%$ of the LTG patients without migraine 


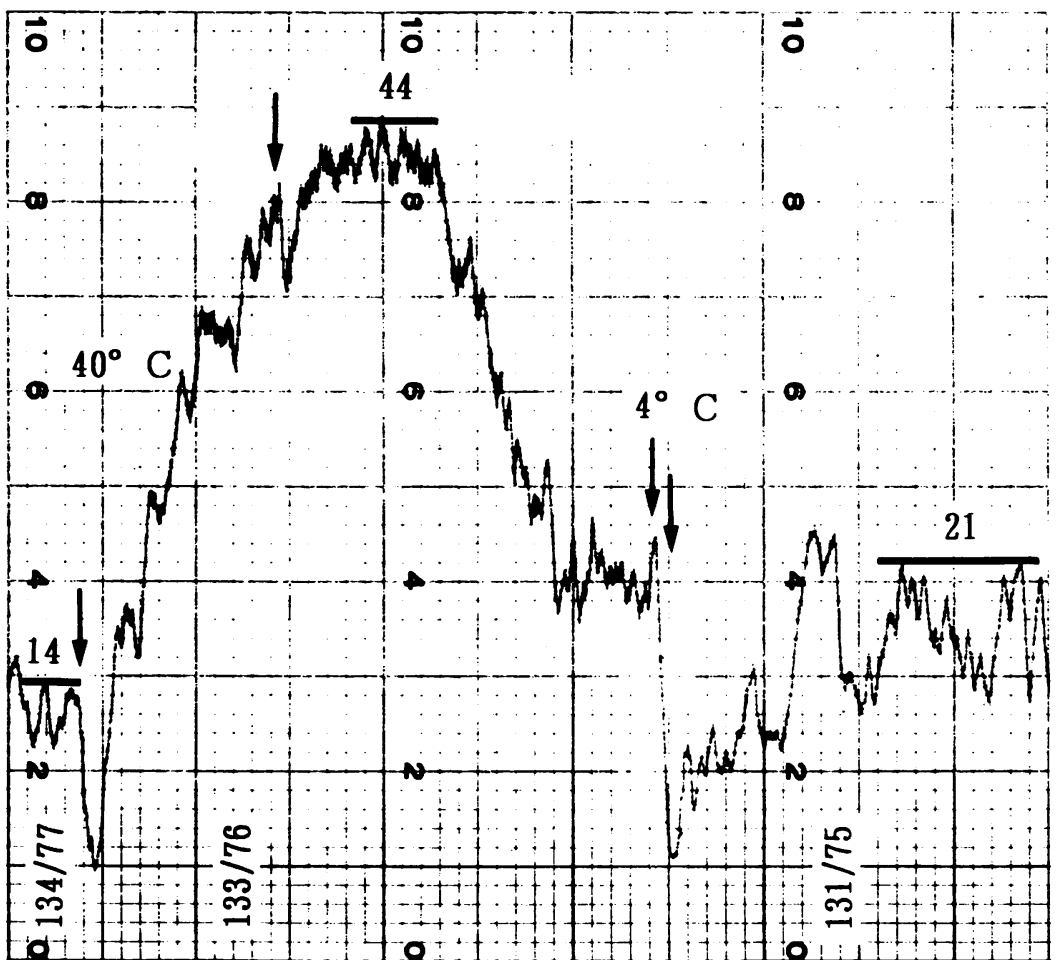

Figure 4 Tracing of finger blood flow in a POAG patient. Vasospastic response was demonstrated. Values of blood pressure were expressed as $\mathrm{mm} \mathrm{Hg}$.

showed vasospastic response, but in our series only $25 \%$ of the LTG patients, $17 \%$ of the POAG patients, and $25 \%$ of the normal subjects showed such a response. In our study the frequency of vasospastic response in normal subjects was almost the same as in the normal subjects in Drance's report (26\%). Patients who showed vasospastic response in our study had no history of vasospastic disease, such as migraine or Raynaud's disease. 'The vasospastic response' which Drance et al designated in their study might not reflect the vasospastic disease.

The pathogenesis of optic nerve damage in POAG is not clear and ischaemic theory has been supported by many ophthalmologists. This theory proposes that elevated IOP produces relative ischaemia of the optic nerve head and damages axons. Therefore the presence or absence of vasospastic response in POAG is an

Table 1 Mean finger blood flow (with $S D$ ) in patients with LTG, POAG, and in normal subjects

\begin{tabular}{|c|c|c|c|}
\hline & $\begin{array}{l}L T G \\
(n=12)\end{array}$ & $\begin{array}{l}P O A G \\
(n=12)\end{array}$ & $\begin{array}{l}\text { Normal } \\
(n=12)\end{array}$ \\
\hline $\begin{array}{l}\text { Age } \\
\text { Baseline flow } \\
\text { Flow after heat } \\
\text { Flow after cold } \\
\text { Flow after heat/ } \\
\text { baseline flow }\end{array}$ & $\begin{array}{l}47 \cdot 7(8 \cdot 6) \\
26 \cdot 2(9 \cdot 8) \\
34 \cdot 0(10 \cdot 4) \\
26 \cdot 3(9 \cdot 4) \\
1 \cdot 42(0 \cdot 49)\end{array}$ & $\begin{array}{c}51 \cdot 7(11 \cdot 5) \\
28 \cdot 0(10 \cdot 8) \\
35 \cdot 8(10 \cdot 4) \\
30 \cdot 3(11 \cdot 6) \\
1 \cdot 41(0 \cdot 60)\end{array}$ & $\begin{array}{c}44 \cdot 0(11 \cdot 6) \\
31 \cdot 0(8 \cdot 7) \\
38 \cdot 9(8 \cdot 0) \\
32 \cdot 6(7 \cdot 7) \\
1 \cdot 35(0 \cdot 57)\end{array}$ \\
\hline $\begin{array}{l}\text { Flow after cold/ } \\
\text { baseline flow/. }\end{array}$ & $1.01(0.12)$ & $1 \cdot 11(0 \cdot 17)$ & $1 \cdot 08(0 \cdot 13)$ \\
\hline $\begin{array}{l}\text { Flow after heat } \\
\text { flow after cold }\end{array}$ & $1.45(0.67)$ & $1.26(0.36)$ & $1 \cdot 23(0.36)$ \\
\hline
\end{tabular}

^The finger blood flows are expressed as $\mathrm{ml} \mathrm{blood} / \mathrm{minute} / 100 \mathrm{~g}$ tissue. important problem to be solved. In our series there was no statistically significant difference in vasospastic response between POAG patients and normal subjects.

Several investigators reported that the vasospastic process caused visual disturbances. ${ }^{1720}$ Lewis $e t a l^{20}$ indicated that $35 \%$ of migraine patients had some form of visual field abnormality, such as left homonymous deficit, generalised depression, arcuate defect, altitudinal defect, temporal sector, nasal steps, and isolated scotomas. Thus ischaemia was generally presumed to be the main cause of the optic nerve damage in LTG and POAG as well. However, it should be noted that, even though there is clinical similarity between ischaemic damage and glaucomatous damage in the optic nerve, the pathogenesis is not always the same. The pathohistology of the optic nerve head has revealed a different pathogenesis. ${ }^{21}$ Our study also failed to confirm the relationship between vasospasm and LTG or POAG.

1 Corbett JJ, Phelps CD, Eslinger P, Montague PR The neurologic evaluation of patients with low-tension glaucoma. Invest Ophthalmol Vis Sci 1985; 26: 1101-4.

2 Phelps CD, Corbett JJ. Migraine and low-tension glaucoma. Invest Ophthalmol Vis Sci 1985; 26: 1105-8.

3 Gasser P. Ocular vasospasm: a risk factor in the pathogenesis of low-tension glaucoma. Int Ophthalmol 1989; 13: 281-90.

4 Flammer J, Guthauser.U, Mahler F. Do ocular vasospasm help cause low tension glaucoma? Doc Ophthalmol Proc Ser

1987; 47: 397-9.
5 Drance SM, Douglas GR, Wijsman K, Shulzer M, Britton RJ. Response of blood flow to warm and cold in normal and low tension glaucoma patients. Am $\mathcal{F}$ Ophthalmol 1988; 105: 35-9.

6 Usui $\mathrm{T}$, Iwata $K$, Shirakashi $M$, Abe $H$. Prevalence of migraine in low-tension glaucoma and primary open-angle glaucoma in Japanese. Brf Ophthalmol 1991; 75: 224-6.

7 Holloway GA Jr, Watkins DW. Laser Doppler measurement of cutaneous blood flow. F Invest Dermatol 1977; 69: 306-9.

8 Low PA, Neumann C, Dyck PJ, Fealy RD, Tuck RR. Evaluation of skin vasomotor reflexes by using laser Doppler Evaluation of skin vasomotor reflexes by using lase
velocimetry. Mayo Clin Proc 1983; 58: 583-92.

9 Sundberg S. Acute effects and long-term variations in skin blood flow measured with Doppler flowmetry. Scand $\mathcal{F}$ Lab Invest $1984 ; 44: 341-5$.

10 Hassan AAK, Rayman G, Tooke JE. Effect in indirect heating on the postural control of skin blood flow in the human foot. Clin Sci 1986; 70: 577-82.

11 Elam M, Wallin BG. Skin blood flow responses to mental stress in man depend on body temperature. Acta Physio Scand 1987; 129: 429-31.

12 Smolander J, Korali PJ. Laser-Doppler and plethysmographic skin blood flow during exercise and during acute heat stress in the sauna. Eur $\mathcal{F}$ Appl Physiol 1985; 54:371-7.

13 Korali PJ. Penetration of unfocused laser light into the skin. Arch Dermatol Res 1985; 277: 342-4.

14 Kashima S, Nishihara M, Takemoto Y, Osawa T. Relationship between the integrated intensity of the power spectrum
of scattered light and tissue blood volume by the dynamic of scattered light and tissue blood volume by the dynamic

15 Hales JRS, Fawcett AA, Bennett JW, Needham AD. Thermal control of blood flow through capillaries and arteriovenous anastomoses in skin of sheep. Pflugers Arch 1978; 378 $55-63$.

16 Hirata $\mathrm{K}$, Nagasaka T. Partitional measurements of blood flow through capillaries and arteriovenous anastomoses in the human skin by laser-Doppler flowmeter. Rep Kowa Life Sci Found 1990; 2: 57-65.

17 Gasser P, Flammer J, Guthauser U, Niesel P, Mahler F, Linder HR. Bedeutung des Vasospastischen Syndromes in der Augenheilkunde. Klin Monatsbl Augenheilkd 1986; 188: 398-9.

18 Gasser $P$, Flammer J. Influence of vasospasm on visual function. Doc Ophthalmol 1987; 66: 3-18.

19 Guthauser U, Flammer J, Mahler F. The relationship between digital and ocular vasospasm. Graefes Arch Clin Exp Ophthalmol 1988; 226: 224-6.

20 Lewis RA, Vijayan N, Watson C, Keltner J, Johnson CA Visual field loss in migraine. Ophthalmology 1989; 96 : 321-6. 21 Iwata K, Fukuchi T, Kurosawa A. The histopathology of the optic nerve in low tension glaucoma. In: Glaucoma update IV. Berlin, Heidelberg: Springer, 1991: 120-4. 